\title{
Canadian Breeding Program for White Pine Blister Resistance in Black Currants
}

M argie L uffman

AdDitional indeX words. genetics, germplasm, R ibes, C. ribicola, cultivar development

SummarY. The search for appropriate white pine blister rust (WPBR) (Cronarti um ribicola J.C. Fischer) resistant germplasm to use in black currant ( $R$ i besnigrum $L$.) breeding programs began in 1935 in 0 ttawa. C rosses were made in 1938 and 1939 with three different $R$ ibes $L$. species and two standard black currant cultivars. The resulting seedlings from these crosses were evaluated for rust resistance. Three promising selections resulted from this program and were named 'C oronet', 'C rusader' and 'C onsort'.

W

PBR affects five-needle white pine (PinusL .) and currant and gooseberry, ( $\mathrm{R}$ ibes). Both Pinus and $\mathrm{R}$ ibes are required hosts to complete the rust life cycle. In $\mathrm{R}$ ibes the disease is more of a nuisance than a serious problem. H owever, WPBR devastates pine production, often destroying the trees. Agriculture and Agri-Food Canada (AAFC) started a program in 1935 to search for germplasm that could be used in a breeding program for rust resistant black currants.

The direction of research carried out by AAFC during its formative years was shaped largely by the first director of the Central Experimental Farm (CEF), William Saunders (Fisher, 1976). The CEF was established in O ttawa in 1887.

Saunders was a druggist by training but he had a deep, abiding interest in horticulture and cereal crops. U nder his tutelage a national fruit experimental program was created. A D ominion horticulturalist position was created to oversee systematic trials of old and new fruit cultivars to improve commercial fruit production and establish regional cultivar recommendation lists. $O$ ut of this program the breeding work for WPBR resistant black currants evolved. M.B D avis, who was the D ominion horticulturalist from 1933-55, worked with A.W.S. H unter on this project.

\section{Results and discussion}

An existing $\mathrm{R}$ ibes plantation at the $\mathrm{C}$ entral Experimental Farm in $\mathrm{O}$ ttawa, $\mathrm{O}$ ntario provided the germplasm for the breeding program. This planting had been previously observed for rust occurrences. O ne bush (R . ussuriense J ancz.), in particular, had never shown any sign of rust infection. T wo other bushes, golden currant ( $R$. aureum Pursh.) and R. odoratum Wendl. were also selected for the program as they were the next least susceptible of all other plants in the block.

Curator, Agriculture \& Agri-Food Canada, Canadian Clonal Genebank Program, Greenhouse and Processing Crops Research Centre, 2584 C ounty Road 20, H arrow, O ntario, N OR 1 G0.

The cost of publishing this paper was defrayed in part by the payment of page charges. U nder postal regulations, this paper therefore must be hereby marked advertisement solely to indicate this fact. 
T able 1. R esults of crosses of three R ibes species and two black currant cultivars (B oskoop G iant and Kerry) to determine white pine blister rust resistance. Adapted from H unter and Davis, 1943.

\begin{tabular}{lcc}
\hline Cross & $\begin{array}{c}\text { Total } \\
\text { no. } \\
\text { seedlings } \\
\text { grown }\end{array}$ & $\begin{array}{c}\text { No. } \\
\text { seedlings } \\
\text { with } \\
\text { rust }\end{array}$ \\
\hline R ibesussuriense x Boskoop Giant & 45 & 0 \\
Ribesussuriense x Kerry & 168 & 0 \\
Kerry x R ibesussuriense & 130 & $6^{z}$ \\
Kerry x R ibesaureum & 12 & 5 \\
Boskoop Giant x R ibes odoratum & 20 & 20 \\
\hline
\end{tabular}

zPresumed to be the result of accidental self-pollination.

In 1938 and 1939, these three plant species were crossed with two standard black currants, 'Kerry' and 'Boskoop' (Table 1). The progeny of the crosses R . ussuriensex 'Kerry' and 'Kerry' $x$ R . ussuriensewere chosen for further evaluation. In 1945, ten of the rust-free seedlingswerechosen for further evaluation on the basis of yield, berrysize, fruit cluster length and evenness of ripening. These 10 were: 0 $381,0-382$, and 0-391 to 0-398; these were established in a yield trial along with the standard $\mathrm{R}$. nigrum cultivars 'C limax', 'Kerry', 'M agnus' and 'Saunders' (H unter 1949). The selections O-381 and O -393 were two of the highest yielding in the trial. These selections were also tested in many other parts of $\mathrm{C}$ anada and $\mathrm{Eu}$ rope and no rust ever occurred. Plants were sent to the $U$ nited States where deliberate inoculations with Cronartium ribicola failed to produce rust(H ahn 1948). 'C rusader' (0-381), selected in 1942, and 'Coronet' (O393), selected in 1943, were named on 9 Dec. 1948 and released in 1949 (H unter, 1949). Both resulted from the R . ussuriense $x$ 'Kerry' cross. D uring the next few years 'Coronet' and 'Crusader' werewidely distributed and grown. It was soon discovered that when whole blocks of each cultivar on its own were planted as opposed to test gardens where several cultivars were planted, problems occurred. As a rule black currantsare self-fruitful although many do require insect cross-pollination for increased fruit set. 'Coronet' and 'Crusader' were almost entirely incapable of self-pollination and flower irregularities hindered insect pollination. In 1951 a third rust resistant cultivar, Consort, was named and released (H unter, 1954). 'Consort', which was tested as $0-396$, had been selected in 1944 and was the progeny of the 'Kerry' $X$ R. ussuriense cross. 'Consort' produced higher yieldswhen planted on itsown and it soon replaced 'C oronet' and 'C rusader' in plantings. I tschief drawback was susceptibility to powdery mildew [Sphaerotheca mors uvae (Schw.) Berk.]; however 'Coronet' and 'Crusader' were also susceptible. Plans were developed to combine resistance to both mildew and rust in further breeding work ( $\mathrm{H}$ unter, 1949).

\section{Literature cited}

Fisher, D.V. 1976. Research bytheC anada D epartment of Agriculture, p. 246-255. In: $\mathrm{H}$ istory of fruit growing and handling in U nited States of America and Canada 1860-1972. Amer. Pom. Soc. RegattaC ity Press, Kelowna, B.C.

H ahn, G.G . 1948. Immunity of C anadian black currant selections from blister rust. Phytopathology 38:453-456.

H unter, A.W.S. 1949. Black currants, p. 26-29. In: Can. Dominion Dept. Agr. H ort. Div. Progr. Rpt. 1934-1948.

H unter, A.W.S. 1954. Black currants, p. 28-29. In: Can. Dominion Dept. Agr. H ort. Div. Progr. Rpt. 1949-1953.

H unter, A.W.S. and M. B. Davis. 1943. $B$ reeding rust resistant black currants. Proc. Amer. H ort. Sci. 42:467-468. 